\title{
Problematization and Research as a Method of Teaching Mathematics
}

\author{
Iran Abreu Mendes ${ }^{{ }^{*}}$, Carlos Aldemir Farias da Silva ${ }^{1}$ \\ ${ }^{7}$ Federal University of Pará, BRASIL \\ * CORRESPONDENCE: $\bigotimes$ iamendes1@gmail.com
}

\begin{abstract}
In this article we present our arguments in favor of a teaching of mathematics by means of problematization and investigation, one that includes in the classroom multiple ways and meanings for the students to read the world around them. In this respect, we propose a teachinglearning process of mathematics grounded on the relationships between society, cognition, and culture, in the way of practices that exercise multiple readings of reality and give meaning to mathematical construction as learning of culture, through culture. Argumentative reflections have lead us to conclude that mathematics characterizes the social and imaginary interactions manifested in culture, under multiple explanatory ways, for the sociocultural experiences, evidenced in the ways of reading, comprehending and explaining the human cultures emphasized by multiple methods and codes of mathematical reading of sociocultural realities. The article is organized in the following way: initial problematization of the study, foundations and assumptions, followed by the epistemological basis of argumentation, on to the appointment of epistemological and didactic implications about problematization, research for a learning beyond disciplinarity, as a way of including these methodological procedures in the classroom. We end with our reflections and referrals for the practice of the mathematics teacher
\end{abstract}

Keywords: problematization, investigation, mathematics teaching, teaching methods

\section{INITIAL PROBLEMATIZATION}

Currently, discussions about mathematics teaching have suggested that the practices to be implemented in the classroom should be realized through the transversality of knowledge. Such an assertion is justified by considering mathematics as a cognitive complex in which manifestations of human thought about the investigation, understanding and explanation of reality are evidenced. To know is a personal act in which human activity becomes essential, insofar as we need to interact with the objects of our surroundings and recombine its characteristic elements in the attempt to build up creations of our imaginative field. It is in the process of permanent reinvention that involves action-reflection-action that we generate knowledge.

A single codification to logically and systematically transmit knowledge to students isolates the points that constitute knowledge as a network one by one, causing fragmentations that come in the shape of different areas of knowledge, rendering connections between the branches of knowledge impossible, creating the different disciplines and isolating the answers obtained along the way. In contrast to this fragmenting, reductive and isolating principle, several teaching methods are suggested which aim to promote the construction of these types of knowledge by students themselves, based on a contextual and globalizing process that gives singular and plural meaning to the ideas constructed.

\footnotetext{
Article History: Received 5 March $2018 \bullet$ Revised 13 April $2018 \bullet$ Accepted 17 April 2018

(c) 2018 The Author(s). Open Access terms of the Creative Commons Attribution 4.0 International License (http://creativecommons.org/licenses/by/4.0/) apply. The license permits unrestricted use, distribution, and reproduction in any medium, on the condition that users give exact credit to the original author(s) and the source, provide a link to the Creative Commons license, and indicate if they made any changes.
} 
In this context, an integrated education constitutes a generating, fomenting principle and a pillar of the transversality of knowledge. Thus, disciplines such as mathematics, physics, chemistry, biology, etc., come to be perceived as several aspects of a kaleidoscope in which many cognitive possibilities of explanation/comprehension of the realities envisioned by the human eye are evidenced. The concept of transversality is then a reflective action in which the context, personal trajectory, the socio-cultural exchanges, the dialogues between the different meanings of the information produced and used in each social context, as well as the importance of this information in all contexts related to the possible themes taken in the light of transversality come to interfere.

In the daily life of the school, it becomes increasingly necessary to give students opportunities to interconnect knowledge, practices and strategies to understand and explain the controversial themes that have arisen in today's global and technological society in which the cloning of human beings, the use of stem cells, biological wars, and the human genome, among other very recent studies, have led to the emergence of worries, curiosities, doubts and anxiety among students due to their absence in the classroom discussions. In the case of mathematics, for example, these themes are considered transversal, and they are certainly allies for the significant development of a globalizing and decisive education for the formation of human values.

Currently, among the questions that are asked by teacher educators, regarding the ways they teach mathematics, we highlight the following: Which teaching methodologies are most appropriate to the moment we live in? To what end do we teach mathematics today? Which didactic actions should be incorporated into the practices of teachers who teach mathematics to meet the social demands we have these days? Why do we need to invest in a teaching of mathematics that promotes the development of skills and competences centered around the autonomy of the learning student? How to promote the development of these skills and competences in the training of teachers who teach mathematics?

These are some of the questions that guided our reflections in this essay so as to point out contributions to forward a didactic approach of teaching mathematics that bets on the exercise of the autonomy of the teacher of mathematics who's undergoing teacher training, aiming that they apprehend from such exercise possible skills and competences that will lead them to develop in basic education a creative activity in the teaching of mathematics.

According to the spectrum of pedagogical ideas present in the various materials elaborated to be used in the training of educators, it is with the purpose of promoting the autonomy of their students that teachers should listen to them more frequently, so as to allow them to interact with materials and ideas, questioning them about what they want, with the intent of finding answers to such questions. Likewise, they should empathize with the point of view of their students and state, with the least possible amount of probability, the solutions to the questions proposed, in order to provoke the exercise of the quest for solutions on the part of their students. Thus, these teachers may tend to centralize their actions on the students, with the encouragement of initiatives and non-controlling communications.

Therefore, teachers who contribute to promote the autonomy of students in the classroom usually nurture the internal motivational resources i.e. the personal interests of the students; they offer rational explanations for the studying of certain contents or for the accomplishment of certain learning activities, using informational, non-controlling language, besides being patient with the students' learning pace.

It is possible to consider, then, that attitudes and actions such as those mentioned above, may contribute to the achievement of a process with a more significant participation of students in their professional training in the most diverse areas of teaching, which can be stimulated through these methodological actions. How are these actions characterized? How can we use them in mathematics teaching? Which contributions can they bring to the training of teachers who teach mathematics?

In order to penetrate the universe of the theme and search for elements that lead us to a better understanding of these methodological actions, we emphasize initially that several authors ${ }^{1}$ admit that these methodologies are considered active because they have the potential to wake the curiosity of the learners as they enter the search for theories about the constructed realities and bring new elements, not yet considered in the classroom or in the teacher's own perspective. These methodologies may stimulate the learning of autonomy and strengthen the student's perception in the problematization of situations involved in school programming, in choosing aspects of study contents, in the possible paths for the development of answers or

${ }^{1}$ For further clarification on this subject see BARBOSA and MOURA (2013); BASTOS (2006) and BERBEL (2011) mentioned in the references at the end of this article. 
solutions to the problems that present themselves as creative alternatives for the conclusion of the study or research, among other possibilities.

There are some characteristic aspects of these methodologies that warrant the reader's reflection, among which we highlight what Bastos (2006) mentions on the subject asserting that it consists of interactive processes of knowledge, analysis, study, research and individual or collective decisions, with the purpose of finding solutions to a problem. In this procedure, the teacher acts as a facilitator or guide to help the students research, reflect and decide for themselves what to do to achieve the intended objectives.

Such methodologies are based on ways of developing the learning process, using real or simulated experiences, aiming at the conditions of successfully solving the challenges arisen from the essential activities of social practices in different contexts. These methodologies are called active, because they have as a fundamental principle to take the actions of the student as the center of learning and the use of problematization as a strategy of teaching and learning, with the objective of reaching and motivating the learner, given that when facing the problem, he or she must halt, examine, reflect, establish a relationship with their personal history and go on to re-signify the solutions found in the explored reality and formalize their conclusions or their discoveries.

Thus, we argue favorably about the act of conceiving and practicing a teaching of mathematics that stimulates the exercise of multiple forms of reading reality, in order to attribute meaning to the paths of mathematical construction in diverse sociocultural contexts, by means of a learning process of culture and through culture. Likewise, we consider mathematics as socially produced knowledge that characterizes the social and imaginary interactions manifested in culture; the multiple explanatory forms for socio-cultural experiences; the ways of reading, understanding and explaining how human culture constitutes itself and the multiple methods and codes of mathematically reading sociocultural realities.

Our initial premise is that scientific and mathematical creation is founded on two principles: problematization and investigation, which consequently have implications for the creation of principles of teaching and learning for school education, also grounded in this process of scientific creation, in which mathematics as a school discipline is structured, based on heuristics and in the problematization and research. From this context, we base the argumentative epistemological bases of our article.

\section{EPISTEMOLOGICAL BASES FOR THE ARGUMENTATION OF THE PROPOSITION}

In order to establish the epistemological basis for the assertion of our premise, however, another question arises: what is this mathematical reading of reality? We understand that it consists of a reading based on principles of mathematical research, curiosity, creativity and complementarity, which implies the exercise of looking at that which is singular and that which is multiple, transversal and globalizing. Such a reading means looking at mathematical activities with the greatest possible number of focuses, from the standpoint of a correlation between society, cognition and culture, such as humanity has done throughout its socio-cultural and scientific history.

In this article, the term creativity in mathematics, referred to in the previous paragraph, refers to the creative processes that, during the course of human history, led mathematicians to seek multiple ways of solving problems that arose socioculturally and which also refer to creation of representations for such solutions as ways of pointing out explanations, as mentioned by Peter L. Berger and Thomas Luckmann (2012) on the social construction of reality; Mario Bunge (2013), while discussing the models and modeling of the relationship between theory and reality; Anthony Storr (2013); when he mentions the dynamics of creation as the process that makes people more authentic; Mihaly Csikszentmihalyi (1998) when he approaches creativity through the lens of its relations with the process of discovery and invention in human ideas and practices and Abraham Moles (1981, 2012), when he discusses the scientific creation and its heuristics and about the sociodynamics of culture, whose ideas about creativity are interpreted as the particular aptitude of the spirit in the sense of rearranging the elements of the field of consciousness in an original and susceptible way of allowing operations in any phenomenal field.

What Moles proposes to us in his arguments on scientific creation is that this creation aims to find a mode of construction by linking a priori judgments which have been put into correlation with successive confrontations with the visible reality. However, it is from the creative thought that the explanatory relations establish themselves with the support of verbal, visual or symbolic languages and through the forms of 
grammatical representations operationalized from these languages. As Moles (1981) proposes, this process of creation corresponds, therefore, to the exercise of maturation of a playful mentality by the scientist.

It is a similar way to that which Claude Levi-Strauss (1989: 32) uses to reflect on the production of knowledge, when he expresses his understanding of how bricoleur thinking is to be operated in the exercise of human creativity for the search of solutions to a practical problem. In this regard, Lévi-Strauss mentions that

The bricoleur is the one who works with his hands, using indirect means if compared with those of the artist. Now, the characteristic of mythical thought is the expression aided by a repertoire whose composition is heteroclite and which, although extensive, remains limited; however, it is necessary that he uses it, whatever the task is, since nothing else is at hand. It thus presents itself as a kind of intellectual bricolage, which explains the relations between the two (Lévi-Strauss, 1989: 32).

Still on this intellectual model, the translators of the 1st edition of this book (Aguiar and Souza) mention that

\begin{abstract}
the bricoleur is the one who performs a work using means and expedients that denounce the absence of a preconceived plan and moves away from the processes and norms adopted by technique. He is especially characterized by the fact that he operates with fragmentary materials already elaborated, unlike, for example, the engineer who, in order to execute his work, needs the raw material (Aguiar and Souza, In Lévi-Strauss, 1989: 32 - footnote).
\end{abstract}

The concept of bricolage (do it yourself), originated from the French term bricoleur, appears in Anthropology referring to the action of combining several elements to form a unique and individualized one, in the exercise of search and representation of the solutions to a practical problem in a sociocultural context, as mentioned above. According to Lévi-Strauss, a good example are the cultures of the new world, in which the bricolage of various cultures (North American, European, Asian, African ...) is established for the formation of a culture that is personal and of one's own identity, as in the process of hybridization mentioned by Bruno Latour in We have never been modern (Latour, 1994).

We reiterate that in the book The savage mind (originally published in 1962 and translated to Portuguese in 1976; the edition quoted here is that of 1989), the French anthropologist Claude Lévi-Strauss used the term bricolage to describe a spontaneous or natural action, besides extending the meaning of the term to include patterns that are characteristic of mythological thought, which does not obey the rigor of scientific thought. The reason is that, as mythological thought is generated by human imagination, it is based on personal experience, and generated by the emergence of things that are preexistent in the mind of the one who imagines them.

The concepts of bricolage and bricoleur make us think about the process of creation in mathematics, since in our studies we consider that mathematical activity is operationalized through a bricolage practice with the purpose of generating forms of explanation in the intention of answering open questions, and thus produce theories about the objects of mathematical thought, for as Caveing (2004) asserts, accessibility to this object becomes possible in the context of the theories that systematize its properties, according to the historicity of the object itself in time and space.

In light of what has been presented so far, I point out that there are three emerging questions to be considered in this process of argumentative reasoning: 1) how is mathematics configured as a descriptive and analytical exercise of society, cognition and culture? 2) from the production of historically generated mathematical knowledge by society, what is the sociocultural characteristic of mathematics today? 3) What is this mathematical activity of creation about after all?

One assumption we hold is that mathematical culture is supported by a principle in which the relationship between society, cognition and culture is the basis that might establish a teaching of mathematics that provides guidelines for a multiple and transversal understanding of nature and human culture. This assumption relies on some paradigmatic subversions with those proposed and experienced by Vergani (1991) and Miguel and Mendes (2010). Our hypothesis is that it is a reading and explanation of reality, that is, a mathematical reading and explanation of reality taken as an integrating knowledge that takes into consideration the relationship between society, cognition and culture, to build the basis that might establish a teaching of mathematics that provides methodological guidelines for a multiple and transversal understanding of nature and culture. 
As for the principle related to the complementarity in this mathematical creation, our way of establishing it is grounded in our interest as educators of teachers who teach mathematics. The aim is to focus on exercises of meta-disciplinary problematization and mathematical investigation in the classroom which, when they are incorporated into teaching activities aimed at content-learning and the practice of subjects related to the teaching of mathematics, as a transversal culture, may offer plural opportunities to apprehend ways of observing, interpreting and exercising the understanding of sociocultural phenomena as practices that might be problematized and solved daily using the relationships between school and society, through the lens of the relationships between Mathematics, Sociocognition and Culture (MSC), as proposed by Teresa Vergani (1991), when she asserts that it is based on the relationship between society, cognition and culture that we might implement a mathematical teaching operationalized by connections between the following sub-areas:

Contextual Mathematics; Mathematics, sociocognition and culture; Structures of logical-mathematical thinking; Mathematics, communication and learning; Mathematics and intelligibility of reality; Development of logical-mathematical thinking; Mathematics as a universal language; Mathematics as non-verbal expression; Computer science; Foundations of statistics applied to education (VERGANI, 1991: 17).

For Vergani, this structural organization corresponds to a model outlined in terms of evolutionary curriculum, for it must be conceived in an organic way and must always be available to the confrontational appeal of the flow of the formative experiences that are formulated, put into practice and evaluated, and may possibly be reformulated according to the evaluation results. It was in this sense that Vergani's proposal included some subareas related to mathematics, starting from the statements generated in diagnoses that were elaborated with the participants of the structuring project of a Department of Mathematical Education at the Higher School of Setúbal (Portugal), an institution dedicated to teacher education.

It is, therefore, about objective human activity that depends on its place in society, its conditions of life, and whose process involves action, reflection and meaning, thus characterizing a triunivocal relationship called socio-cognition-culture (Vergani, 1991), or biunivocal as sociocognition-culture.

The relationships between society, cognition and culture (where mathematics is inserted, as a sociocultural practice) are the central focus of Teresa Vergani's thought, which is present in the books The Zero and the Infinites: an experience of Anthropology and Intercultural Mathematics Education (1991) ) and Excrement of the sun: on the subject of cultural diversities (1995). In these publications, Vergani puts mathematics at a cultural level originated from social, cognitive and cultural intertwining, as if it were a threedimensional projection in which the human heritages we call culture, society and cognition operated in multiple combinations so as to generate explanatory, reflexive and projective information about life on the planet.

If we reflect on the sociocultural and formative relationships that appear in the aforementioned proposal, we will immediately realize how necessary it is to think of mathematics as a sociocultural phenomenon to be discussed in teacher training, based on six moments: 1) the history of humanity: the origin of natural and experimental explanations in social and imaginary interactions - Culture; 2) justified knowledge: the emergence of explanatory currents and philosophy - Thought as culture; 3) knowledge tried, justified and validated - Science as culture; 4) the types of Mathematics before and after; 5) Education and dialogue between these types of knowledge; 6) mathematical education as an opportunity for dialogue between the emerging types of knowledge and existing mathematics.

Each of the lenses used by society, teachers and researchers, and according to the historical-cultural sources they use, may point out the paths of mathematical construction in daily, scholarly and scientific contexts. This movement consists of looking at the historical-cultural process of development of mathematical activities, under the widest possible focus, considering learning as a sociocognitive integration exercise in three dimensions: society, cognition and culture, which may provide a procedural dynamic of cultural apprehension through mathematical reading.

If we look at the Figure 1 descriptor we will realize that, implicit in it, are the explanatory relationships established by the three types of heritage taken as axes of configuration of the objects of mathematical studies that, according to each elaboration can characterize each object in question in simple or conjugated approaches, according to its specifications. In each situation, therefore, we can have a representation of the object of study, according to the lens through which the studied object is read. This reading movement of the objects of interest in mathematics has been generating aspects, either priority ones or not, in the mathematical 


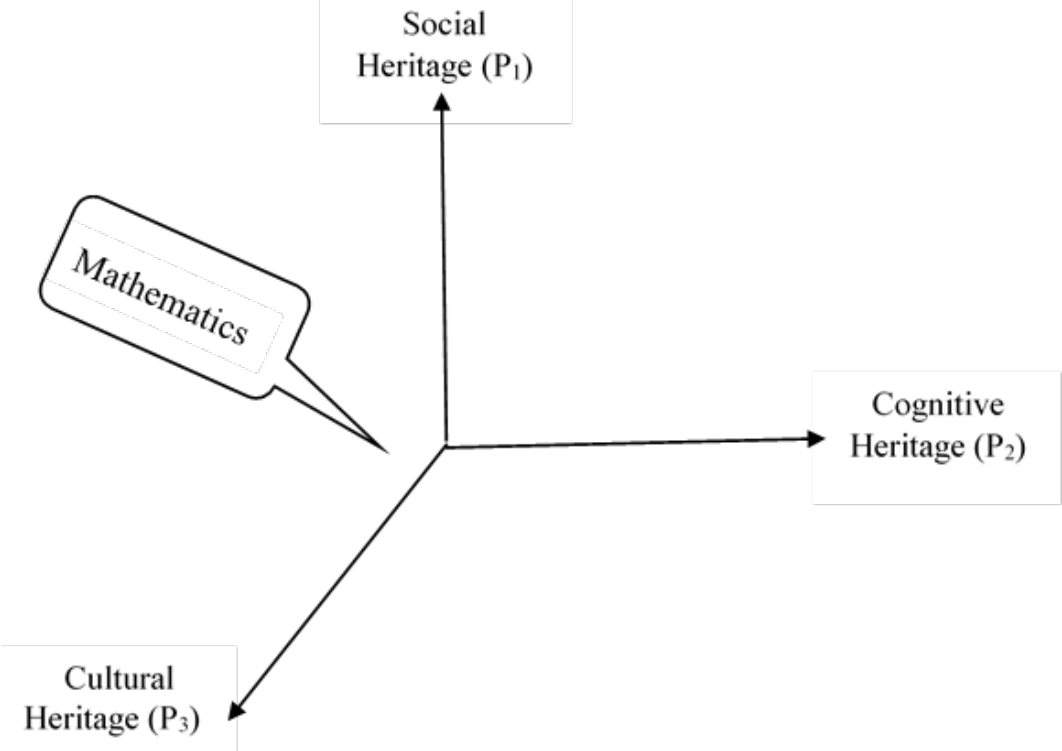

Figure 1. Mathematics emphasized in the relationship between Society, Cognition and Culture Source: Descriptor prepared by the authors

studies focused on the school, the different levels of teaching and on research about mathematics teaching and mathematical culture in its broadest sense. Let's see a little more of these relationships.

\section{EPISTEMOLOGICAL AND DIDACTIC IMPLICATIONS}

If we observe the mathematical practices represented in Figure 1, we will identify a $\mathrm{P}_{1} \mathrm{P}_{2}$ approach that denotes a facet in which emerge implications related to the teaching of mathematics in teacher training and basic education that deal, individually and in combination, with two approaches : the social and the cognitive one, and these implications may be taken into consideration by the teacher and the researcher as a means of establishing sociocognitive relations originated in these mathematical practices, in order to offer elements of comprehension of mathematics in its sociocognitive dimensions based on the exercise of a social thought about mathematics that is to be taught and/or learned.

On the other hand we notice that the $\mathrm{P}_{1} \mathrm{P}_{3}$ approach offers an environment of identification in which to reflect on possible implications regarding the teaching of mathematics in teacher training and basic education that explore mathematical practices focused on two other individual or conjugated approaches: the social and cultural ones, exploring possibilities of teaching and research that may establish socio-cultural relationships around these mathematical practices, so as to offer elements of the comprehension of mathematics in its sociocultural dimensions based on the exercise of a social and cultural thinking about the mathematics that is to be taught and/or learned.

In a third approach we observe the $\mathrm{P}_{2} \mathrm{P}_{3}$ relationship in which it is possible to reflect on its implications regarding the teaching of mathematics in the formation of teachers and in basic education, as well as in the research of this area, that can explore mathematical practices in their individual aspects dealing with cognition or culture, and which mainly combine the two approaches: the cognitive and the cultural one, in order to establish cognitive relationships that emerge from the cultural impregnations around these mathematical practices i.e. mathematical enculturations, as Alan Bishop (1999) suggests, so as to offer elements of mathematical comprehension in its cultural cognitive dimensions based on the exercise of a cultural thought about the mathematics that is to be taught and/or learned.

If we also consider the possibilities of connections between $\mathrm{P}_{1} \mathrm{P}_{2}$ and $\mathrm{P}_{1} \mathrm{P}_{3}$ with regards to the research and teaching of mathematics in teacher training and basic education, we will be able to discuss which integrative aspects of contextual mathematics might have its exploration and comprehension expanded. It is therefore a double conjugation in which socio-cognitive and sociocultural relationships might contribute more broadly for the extension and foundation of the intercultural and multicultural relationships that constitute the 
mathematical practices and what possibilities may emerge from these relationships for the research and teaching of mathematics.

Another relationship that is doubly conjugated and of extreme importance refers to the connections between $\mathrm{P}_{1} \mathrm{P}_{2}$ and $\mathrm{P}_{2} \mathrm{P}_{3}$ with the perspective of broadening our understanding of sociocognitive and cultural relationships, which can be treated in an integrated way, leading to the emergence of connections that allow a deeper perspective in the way we look at the mathematical practices researched and used to approach contents referring to the teaching of Mathematics in teacher training and in basic education. The same is implied in the double connection between $\mathrm{P}_{1} \mathrm{P}_{3}$ and $\mathrm{P}_{2} \mathrm{P}_{3}$ concerning the search for a broader and deeper look in the research of the conceptual aspects regarding the teaching of Mathematics in teacher training and in basic education.

One question, however, remains: how to materialize these relationships in the formation of the mathematics teacher and in the teaching actions in basic education?

Some possibilities for the establishment of these relationships point out that it will be necessary to elaborate a plan of action for the exercise of identification and interpretative description of these relationships and connections of practices and knowledge that originated school knowledge, so as to ground a teaching of mathematics that causes ruptures in the current paradigm, as a challenge to the regional context, i.e. as a new way of building mathematical learning from a combined local-universal perspective, based on the intercultural and multicultural aspects related to the problems investigated by academic mathematics.

According to what Bishop (1999) proposes, we can admit isolated approaches to mathematics if we disregard its enculturation process, which occurs in an integrated way in the involvement of cultural, societal (referring to social groups themselves), institutional, pedagogical and individual contexts, for it is in the relationships established by these five intervening factors that the teaching of mathematics will be able to deal with matters of sociological, ideological, scientific, technological and affective order. It is in this body of meanings that mathematics is immersed, from a dialogical outlook, that we consider the possibility of broadening the interpretation of codes that contribute to an approach of mathematics teaching centered around these epistemological levels: local, regional and universal.

Still on these aspects Vergani (1995) proposes that the universalizing principle admits that the world civilization can be no other than the (co)relation, the world scale, of each and every culture preserving its own originality or singularity. Therefore, we admit that the educational system must promote the development of attitudes and values that shape educators capable of creating viable means for the development of students of any cultural origin.

An effort of this nature was made by Vergani (1991, p.18), in proposing a teacher training in action, whose constructive process was structured on the basis of listening to the teachers themselves and considering previously mentioned aspects such as contextual mathematics and MSC, in the development of logicalmathematical thinking and communication in the learning process in search of intelligibility of reality, taking into special consideration non-verbal expression and informational languages.

It is possible to notice there several integrating implications are highlighted in which we can correlate the ideas reflected in Figure 1 to the aspects highlighted by Vergani (1991), in order to establish pedagogical contributions that may be used as matrices of curricular and didactic reorientation to be practiced in the training of mathematics teachers and in its developments in math classes in basic education. However, the relationships and reflections established by the educators and by the mathematics' teachers in training (initial or continued) cannot be operationally implemented so as to achieve implicit objectives if they are not associated with principles that mobilize a dynamic, active and experimental exercise of those who practice them. In this sense we consider the insertion of problematization and investigation with a metadisciplinary approach essential to our proposal, based on the principles originated from the propositions previously enunciated.

\section{ON PROBLEMATIZATION, INVESTIGATION AND METADISCIPLINARY LEARNING}

As we have already mentioned in the previous section, the proposal originated in the relationsships established in the discussions hitherto announced evidences the necessity and value of implementing a reorientation and innovation in the didactic approach in mathematics teaching considering the context of local, regional and global practices, in their relationship with the challenge of multiculturality.

For this orientation to be put into practice, it is decisive to realize that the understanding of the present world is at the same time among the school disciplines, in the different school disciplines, and beyond any 
school disciplines, that is, it is in a dialogical conformation among them and the same time in an integration that shows itself in non-disciplinary contours, that must be inserted in the mathematics classes in the shape of generating thematic units or as thematic research projects in which the studies of reality might be taken as guidelines for a sociocultural perspective in the teaching of mathematics.

To mention examples of this investigation and problematization for mathematics teaching, we emphasize again that it is a matter of putting into practice the exercises of investigation and problematization of mathematical practices, related to the contextual situations where actions emerge that are practiced by liberal workers such as salespeople, builders, farmers, especially those related to geometries and systems of agrarian measures; professional practices operationalized in building; the practices related to the production in the arts of weaving shapes and measures as in the several handicrafts with vegetal fibers in general, mainly the indigenous cultural practices that involve geometric concepts, measures and symmetry.

Based on the reflections established in our research experience for three decades and taking into account the non-disciplinary practices that are the subject of the thematic investigations carried out, we assure that at any level of teaching such classroom practices demand from the teacher a clear conception of what this practice is, how to execute it properly and of what kind of evaluation he or she will be able to operate in order to check the production of knowledge in the classroom. An investigative project arises with the perception of a problem and an opportunity to solve it, even if it takes weeks, months or years for its resolution and final evaluation, often giving rise to new projects. The consolidation of this pedagogical practice presumes to start from a minimally favorable context in which teachers and students are capable of dealing with uncertainty and, above all, make a major investment in the planning and execution of research activities from a metadisciplinary perspective.

How is it possible to carry out a non-disciplinary investigative practice in the classroom? The project as a training modality aims to develop investigative activities centered around the experimental reality of school and/or community life within the scope of educational training, and stimulate cooperative teamwork and metadisciplinary dialogue. It also aims to increase the capacity to solve problems and develop action plans, aiming to deepen the ability to relate knowledge and action, learning and production, considering the potential of affective integration, socialization and the accomplishment of personal and group interests.

Emphasis should be placed on student autonomy, decision-making and action execution. The teacher should support the students in building this autonomy and its potentials, generating rich attitudes of questioning and hypotheses in light of significant learning experiences. In this perspective education tends towards methods that develop decision making and attitudes with the students and the contents are no longer organized in a linear and decontextualized way. With the projects, we begin to treat with the students, too, those topics that nobody wants to take upon themselves because they are not in the disciplinary contents, namely: ethics, solidarity, companionship, responsibility, among others, without losing sight of the particularities of each area.

The disciplinary contents are treated in a global way, without disciplinary specification (specific content or discipline), for they arise naturally, during the development of the work, that is, in the problematization, in the execution and in the discussions about the evidenced results, when one organizes and formalizes the working contents along with the students, aiming to check what was significant for the student and consequently apprehended. In this moment the teacher is only the supervisor of the work and his main concern will be to guide the choice of project in order to make it possible to carry out the research activity and to awake the interest of the students, leading them to the action and the planned practices with a view to the development of the capacity of observation, reasoning, method of work, initiative, self direction, creativity, cooperation, responsibility and self expression of students.

Regarding the relationships between the practice of problematization and its impacts on the mathematical learning of students, both in basic education and in undergraduate mathematics, from our experiences and reflections, we assure that these practices put students in contact with the information and the production of knowledge, mainly in order to solve the impasses and promote their own development. Learning through problematization or from open problems in your area (mathematics) or any other is therefore one of the possibilities for active involvement of students in their own formation process.

As to the impact of these methodologies on student formation, we emphasize that student engagement in regards to new learning, through understanding, choice and interest, is an essential condition to expand their possibilities of exercising freedom and autonomy in decision making in different moments of the process that they experience, preparing them for future professional practice. This is one of the emphasis that has been 
given to teaching to lead the student to learn from open problems or problematic situations of reality in the last two decades and that finds part of its basis in the principles established by the active learning of John Dewey (1859-1952), and later by the proposals of Paulo Freire (1996) to stimulate the development of a problematizing pedagogy, sustained by the conception that both educator and the apprentice learn together, in a dynamic relationship practice, guided by theory, redirects this theory, in a process of constant improvement. Likewise, the principles derived from Stenhouse's theories (1987) about research as a basis for teaching, with emphasis on the elaboration, execution and evaluation of thematic research projects.

On the ways of practicing such principles and methods in teaching actions, in mathematics teaching, we propose that the elaboration and use of Basic Problematization Units (UBP) be included in the practice of the mathematics teacher. What is a UBP? Regarding the production and use of UBP, according to Miguel and Mendes (2010), it is a teaching and learning process that involves the mobilization of thematic problematizations from the exploration of social practices in mathematics classes in an integrated and globalizing sense.

In the next section we will discuss aspects about what Miguel and Mendes (2010) propose in regards to these insubordinative practices that can be worked out in the training of mathematics teachers with developments for basic education.

\section{INVESTIGATIVE PRACTICES THROUGH BASIC UNITS OF PROBLEMATIZATION (UBP)}

Regarding the teaching and learning process, several researches and didactic experiences have shown that the mobilization of problematizations stemming from the exploration of socio-cultural practices contribute to the construction of a network of conceptual and metacognitive meanings involved in the solution of problems. However, in order to be used in the school environment, these practices should not be chosen at random, they should be part of personal and social needs as well as the solution of problems similar to those that afflict the families of the students themselves, such as: the precariousness of basic sanitation; lack of security; the difficulty of access to the health care system, among others, or even future problems, for example, how to prevent the collapse of a city's water supply.

It should also be pointed out that in choosing a practice, such a practice should not necessarily be tied exclusively to mathematics or any other school subject, since, as we have already mentioned, the nature of the chosen theme does not have to be necessarily disciplinary but relevant to the purposes of the teacher, since it will be chosen intentionally. According to Miguel and Mendes (2010), the use of problematization contributes to the construction of a network of conceptual and metacognitive meanings involved in solving problems, for the practices proposed by them, denominated UBPs, aim to lead students to the exercise of thinking. For the authors, the nature of the topic to be problematized should not be characteristically disciplinary, that is, it should be independent of any particular discipline. Therefore, we recommended the proposition of themes that may lead students in search of solutions to problems involving real problematic situations that afflict some communities in our society in the shape of problems to be proposed, for example, in undergraduate courses.

Still in this topic, the authors reiterate that a UBP cannot be understood as if it were a conventional list of school or academic exercises to be solved in or outside the classroom. It is a scripted invitation for the students to move towards the problematization. In teacher training courses in scientific and technological areas, for example, we can explore mainly social and historical practices linked to human activities such as nautical, agricultural, economic-financial, commercial, topographical, astrological-astronomical, mysticalreligious, political, artistic, military, games in general, among others, materialized in the form of educational and scientific investigation, in order to be able to mobilize the contents in a sociocultural approach more open than those established in school activities.

The same UBP can be explored in secondary and higher education. For this, the teacher should highlight among the activities related to the UBP social practices, those that contemplate the contents addressed in each period, and he or she can present them in a flexible way to the context of the student. During the implementation of the activities, solutions with imperceptible levels of depth may emerge. However, these levels that the discussions may reach arise in a spontaneous and differentiated way for each UBP studied. Such discussions may contemplate several points of view according to the individual experiences of each participant and due to the nature of the chosen practice. The more the chosen practice is detached from any particular discipline, the greater the number of questions presented will be. 
In the process of building solutions to the problems proposed through the UBP, students will be fatally permeated by the contents contemplated by the activity. Thus, it is possible to develop skills in our students in a conscious way, that is, they will know why they are studying certain contents and, in this way, the activity can become unforgettable for them.

In our didactic practices that involve the use of UBP in the initial and continuous training of teachers who teach mathematics, one of the particularities evidenced concerns the fact that to carry out a problem-solving session, we usually present to the students a problematic contextual situation, in which not always the issues related to the intended problematization are explicit. From this situation we propose to the students a block of questions that will guide the execution of the research planned by the teacher. At this point, we suggest that the students read the material and write any interrogative notes that may come up during reading. Based on the partial results presented by the students, the teacher should lead to further actions in order to guide, whenever necessary, the information surveys or more in-depth studies on the subject to be problematized, always taking as central focus the search for answers for the questions that make up the proposed UBP.

\section{Examples of Problematizations and Investigations Elaborated as a UBP}

In the following, we present examples of UBP, or rather, flashes of explored contexts, problematizations and questions that may challenge the teacher in training in the process of elaboration and didactic use of a UBP that involves socio-cultural problematization.

\section{UBP 01: From the magnificent canonical description on logarithms and their problematization}

In the preface to the book Mirifici Logarithmorum canonis descriptio (Magnificent canonical description on logarithms), originally published in 1614, John Napier presents his considerations about being a mathematics scholar, since for him nothing was as painful to people as the practice of mathematics, because the logistics were somewhat as slowed down as they were postponed because multiplications, divisions and extractions of square or cube roots involved large numbers, which were subjected to the tedium of long operations, and even more so to the uncertainties of errors. So Napier sought to discover through what safe and rapid process these obstacles could be overcome. With this purpose he elaborated a logarithmic board, that is, a small table of values by which we can obtain a knowledge of all the dimensions and geometric movements in space, through a very easy calculation. The table was derived from numbers that progress in continuous proportion: one is arithmetic, that which proceeds at equal intervals, and another geometric, which proceeds at unequal and proportionally increased or decreasing intervals.

Starting from the discussion flash previously presented, we follow with the proposition of questions and inquiries, in order to guide a process of problematization and investigation of several aspects concerning the development of concepts, properties and arithmetic, algebraic and geometric operations that involve the logarithms.

Let us look at these questions and try to organize an investigative work based on the proposed questions.

1. Who was Napier? Why did he become famous? How is his name related to Mathematics to this day?

2. A logarithmic table is a small table through which we can obtain knowledge of all geometric dimensions and movements in space, using a very easy calculation. It is extracted from numbers progressing in continuous proportion. What is the etymology of the word logarithm?

3. State explicitly the notions of arithmetic progression and geometric progression mentioned in the previous excerpt.

4. Based on the progressions Napier has shown it to be possible to calculate the logarithms (in base 10) of the known powers of 10. Briggs in 1624, in his Arithmetica Logarithma, following Napier, calculated by hand the sequence of the following 54 square roots: $10^{1 / 2}, 10^{1 / 4}, 10^{1 / 8}, \ldots, \quad 10^{(1 / 2) 54}$, whose logarithms he knows: ... 0.5,0.25,0.125, .., $1 / 2^{54}$. Repeat these calculations and arrange the whole process into a worksheet.

5. It continued to be for Briggs, the calculation of the logarithms of the intermediate values among these of 10 using the properties of the logarithms to obtain logarithms. Illustrate this idea, always with a worksheet. Then calculate the logarithm of the product of two successive values of the table accomplished in the previous point to obtain new ones. 
Other Problematizations

1. A ruler to be calculated on paper

On a piece of squared paper, copy and cut the pattern shown below. Then cut along the red line as well.

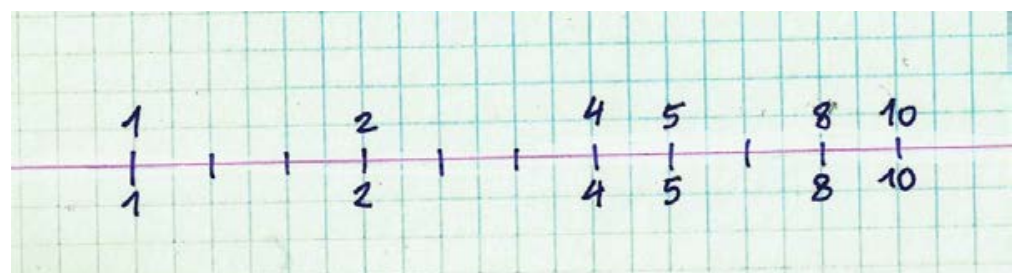

a. Find out how this little device allows you to perform some multiplications.

b. Deduce how we can complement this ruler in order to calculate to which values do the other features without numbers correspond.

2. The energy consumption of a country is doubled every 20 years.

a. What is the annual rate of increase?

b. How long does it take to see this $50 \%$ increase in consumption?

c. How much did this consumption multiply after a century? And after two centuries?

3. The world's population surpassed the one billion mark in 1804, the two million one in 1927, the three million one in 1960, the four billion one in 1974, the five billion one in 1987, and the six billion one in 1999. [appropos of information the projections show that in -5000 there were about 5 million human beings; 100 million in -750; 200 million in 400; 500 million in 1650].

a. What is the rate of increase between the 2 nd and 6 th billion?

b. If that rate remained constant, what would the world population have been in 1960 ? 1974? 1987? 1999 ?

c. According to the same hypothesis (constant rate), in what year the 3 billion would have been achieved?

d. When will 7 th billion be achieved if this rate is maintained?

e. The Earth has an area of about 130 million $\mathrm{km} 2$. On what date will there be only one square meter per inhabitant?

4. During a survey of the population of a rural municipality, the number of inhabitants decreased by about $5 \%$ per year.

a. By keeping this decrease of $5 \%$ and given that $\mathrm{H}(0)$ is indicating the number of inhabitants at the beginning of the first year of study, $\mathrm{H}(1)$ the number of inhabitants at the beginning of the following year, etc., calculate $\mathrm{H}(1), \mathrm{H}(2) \ldots$ and express $\mathrm{H}(\mathrm{t})$ as a function of $\mathrm{t}$.

b. Consider the case $\mathrm{H}(0)=10.000$ and calculate the approximate value of $\mathrm{H}(1)$ and $\mathrm{H}(10)$.

5. Three-quarters of the radioactive atoms of a block of Thorium are disintegrated in 33600 years. The amount of radioactive atoms as a function of time is given by the law:

$$
N(t)=N o \cdot(1-r)^{t}
$$

where $\mathrm{r}$ depends on the radioactive substance.

a. For how long half the atoms in this block has been disintegrated?

b. In how long half of the remaining will be disintegrated?

6. If one considers a city that has $\mathrm{P} 0$ inhabitants and the population growth rate of that city is $\mathrm{i}$ (in \%) per year, a population $\mathrm{P}$ is obtained after $\mathrm{t}$ years according to the equation:

$$
P=P_{0} \cdot\left(1+\frac{1}{100}\right) t
$$

Suppose that a city had a population of $\mathrm{P} 0=12.000$ in the year 2000 and an annual growth rate of $5 \%$.

a. What will be the number of inhabitants in 2020 ?

b. What was the population in 1997 ?

c. How many years will be necessary for the number of inhabitants to double, compared to the number existing in 2000 ?

d. Suppose the city had a population of $\mathrm{P}_{0}=200.000$ in 2000 and ten years after it has 450.000 inhabitants. Calculate its growth rate (in \%) per year.

e. Two cities A and B have, as of January 1st, 2010, the respective populations of 100.000 inhabitants and 80.000 inhabitants. The population of $\mathrm{A}$ increases by $1 \%$ per year, while that of $\mathrm{B}$ increases by $5 \%$ per year. $\mathrm{A}(t)$ is the population of city $\mathrm{A}, t$ years after 2010 and $\mathrm{B}(t)$ is the population of city $\mathrm{B}$, 
years after $2010 . \mathrm{A}(t)$ is the population of city $\mathrm{A}, t$ years after 2010 and $\mathrm{B}(t)$ is the population of city B, years after 2010. Determine the starting year for the number of inhabitants of B to exceed the number of inhabitants of $\mathrm{A}$.

\section{UBP 02: Institution of cultural object function ${ }^{2}$}

The development of the cultural object known as function in history can be considered in two distinct qualitative moments: 1) when, with the advent of modern science in the West, it was informally mobilized by scientists in their practices of quantitative modeling of dynamic natural phenomena, manifesting itself through rhetorical enunciations or analytical expressions of natural laws; 2) the moment from which this object started to be explicitly and independently thematized, that is, disconnected from the original contexts of activity in which it was somehow mobilized, starting to be investigated from the point of view of the specialist mathematicians, with the purpose of making it participate in a general, abstract, and internally consistent theory.

1. Explain, in detail, why, according to Bento de Jesus Caraça, the ancient Greeks would not have managed to mobilize the cultural object function.

2. Why do some historians consider that ancient peoples, such as the Babylonians and Greeks, would have implicitly used the mathematical object function? Do you agree with this point of view? Present arguments against or in favor of it.

3. Explain why and how, according to Bento de Jesus Caraça, did the cultural object function appeared and developed only from the advent of Modern Science, connected to the notion of natural law.

4. Explore and discuss comparatively the four following contexts in which the cultural object function is mobilized with the purpose of practicing the quantitative modeling of various dynamic phenomena and expressing them rhetorically and analytically through natural laws or mathematical propositions. In what terms do you analyze what would the perception have been like that diverse natural laws could be represented by a same analytical expression that would have motivated the theoretical investigation of the constitution of a general and abstract theory related to cultural object function?

5. Analyze the evolution of the concept of function in the mathematical and philosophical domain. Locate situations that emphasize the presence of the notion of function in natural and social sciences, describe and comment on its characteristic mathematical aspects. Discuss the importance of the concept of function in today's mathematics.

\section{Other Problematizations}

\section{Context 1}

What is the analytical expression that allows one to determine the distance covered by a free falling body in relation to time, when the initial velocity and the initial space covered by it are null?

\section{Context 2}

What is the analytical expression that allows one to determine the kinetic energy of a body in relation to its speed?

\section{Context 3}

What is the analytical expression that allows one to determine the amount of heat generated in a conductor, in the unit of time, in relation to the intensity of the current that passes through it?

\section{Context 4}

What is the analytical expression that allows one to determine the area of a right triangle to be determined as a function of an acute angle $\hat{\mathrm{A}}$ and of the leg adjacent to this angle?

\section{REFLECTIONS AND REFERRALS}

The experiences related to the use of this method of teaching in the initial and continued formation of Mathematics teachers mentioned in this article, are based on the research and teaching actions carried out

\footnotetext{
2 Adapted and amplified by Iran Abreu Mendes from the first version originally elaborated by Antonio Miguel, with additions of information and questions.
} 
since 1993, in courses of formation of teachers of Mathematics ${ }^{3}$. The term research was mentioned in the sense of characterizing an exercise of quest and reflection for learning, that is, a continuous exercise of exploration of nature and culture as a way of apprehending the world. This is because, increasingly, our experience with the mobilization of historical and cultural investigations in the initial formation of teachers of Mathematics has stimulated us to practice mathematical investigation in the classroom, in order to relate it to other practices that favor the transversalization of Mathematics. Another reason to not segment research is that, in the way we have mobilized sociocultural practices in these experiences of teacher training, we are always connecting mathematics to the exploration of practices carried out in the context of different, therefore nondisciplinary human activities. Besides, we consider that in school education and, by extension, in teacher training, we must pay attention to the formation of the citizen, who must learn to problematize different ways in which mathematics is involved and is mobilized in different human activities.

Our concern with this type of study arose when we decided to explore mathematical aspects related to the diverse socio-cultural practices, at which time we conducted historical surveys about some practices, following with the local investigation and finally in the systematization of the information obtained, with a view to its mathematization in classroom. Thus, a question has arisen: is it possible to investigate these socio-cultural practices under an epistemological and didactic approach to school mathematics? How can these practices, when explored and systematized, be used to build courseware to teach mathematics in basic education, as well as in the training of the mathematics teacher? Based on the experiments carried out we propose the experimentation of such investigative and didactic actions in the formation of the Mathematics teacher at undergraduate and postgraduate levels. In this sense we consider it necessary to establish and analyze the didactic and epistemological connections for the construction of a pedagogical work mediated by the researcher professor that involves postgraduate students, undergraduate students in Mathematics or another similar course, in the subjects related to the teaching of mathematics for the students of basic education.

Bibliographical research exercises are extremely important for the effective accomplishment of the elaboration of UBP in initial and continued teacher education, as well as its implementation in mathematics classes in basic education. Our assertion is grounded on the fact that the products generated in thematic bibliographic research constitute the main subsidy for teachers to establish research and problematization as the basis to effect a teaching and learning that relies on the exploration of information related to the sociocultural and professional practices, in the form of problematizations, in order to contribute in overcoming the conceptual and didactic difficulties of these teachers in the exercise of teaching itself, as well as doing an exercise of mathematical creativity in their classroom practice.

In this sense, we assure that the bibliographical survey contributes as a first step in the search of information that will lead the students to the practices of reading and establishing thematic discussions on the socio-cultural contexts and their mathematizations, through investigation and problematization in the teaching of mathematics. We hope that the discussions and reflections originated from the propositions mentioned in this article will contribute to the accomplishment of a significant work in regard to problematization in the classroom through the UBPs, which might stimulate the conceptual construction for undergraduate students in Mathematics and for the teachers who work in basic education.

Based on our reflections about the experienced practice, we ensure that the mathematical investigation and problematization of socio-cultural practices involving the local environment in the vital connection societycognition-culture constitute an important generator of a broad process of creation, discovery and learning; an exercise of a problematizing heuristic that activates creative processes in Mathematics. Likewise, the use of research should be taken as a constructive principle in the integral formation of the student in a process of mathematics teaching at all school levels that might imply a plural learning in which Mathematics is a reading of the world that is complemented by the other readings in an integral and integrated way.

On the other hand, we understand the reformulation of the practice of the Mathematics teacher through a dialogue between the local-regional context and didactic activities based on guided research, connecting Mathematics to other school subjects. Likewise, the exploration of regional aspects by school mathematics reduces the frontier between local and universal knowledge; the dialogical interaction between them offers a

\footnotetext{
${ }^{3}$ We refer to the topics Topics of History of Mathematics, History of Mathematics Education, Didactics of Mathematics and Epistemological Foundations of Mathematics, which integrate the training courses of Mathematics teachers of the Federal University of Rio Grande do Norte, as well as the disciplines History of Mathematics Mathematics, Special Topics in Mathematics Education, among others already mentioned in other courses of other universities where I was previously professor.
} 
more abundant field for investigation and, consequently, important implications for the achievement of satisfactory results for the teaching of mathematics.

It is, therefore, through this type of practical proposal that we admit that it is possible to constitute a process that characterizes a globalizing mathematical education. These are just a few ways of learning to look, think, imagine, problematize, and think about Mathematics as human culture. If we do not subvert the current order given at school we will not be able to meet the clamor of the sociocultural needs that knock on the door of our classroom.

\section{Disclosure statement}

No potential conflict of interest was reported by the authors.

\section{Notes on contributors}

Iran Abreu Mendes - Federal University of Pará, Brasil.

Carlos Aldemir Farias da Silva - Federal University of Pará, Brasil.

\section{REFERENCES}

Barbosa, E. F., \& Moura, D. G. de. (2013). Metodologias ativas de aprendizagem na Educação Profissional e Tecnológica [Active learning methodologies in vocational and technological education]. B. Tec. Senac, Rio de Janeiro, 39(2), 48-67.

Bastos, C. C. (2012). Metodologias ativas [Active methodologies]. Retrieved from http://educacaoemedicina.blogspot.com.br/2006/02/metodologias-ativas.html

Berbel, N. A. N. (2011). As metodologias ativas e a promoção da autonomia de estudantes [Active methodologies and the promotion of student autonomy]. In Semina: Ciências Sociais e Humanas. Londrina, 32(1), 25-40.

Berger, P. L., \& Luckmann, T. (2012). A construção social da realidade [The social construction of reality]. 34. ed. Tradução Floriano de Souza Fernandes. Petrópolis: Vozes.

Bishop, A. J. (1999). Enculturación matemática. La educación matemática desde una perspectiva cultural. Trad. Genís Sánchez Barberán. Barcelona, Espanha: Paidós.

Borasi, R. (1992). Learning mathematics through inquiry. Portsmouth, NH: Heinemann Educational Books.

Caveing, M. (2004). Le problème des objects dans la pensée mathématique. Paris: Librairie Philosophique J. Vrin. (Série Problèmes et Controverses)

Csikszentmihalyi, M. (1998). Creatividad. El fluir y la psocilogía del descubrimiento y la invención. Tradução José Pedro Tosaus Abadia. Barcelona: Paidós.

Freire, P. (1996). Pedagogia da autonomia: saberes necessários à prática educativa [Pedagogy of autonomy: knowledge necessary for educational practice]. 13. ed. Rio de Janeiro: Paz e Terra.

Latour, B. (1994). Jamais fomos modernos. Ensaio de antropologia simétrica [We were never modern. Symmetrical anthropology essay]. Tradução Carlos Irineu da Costa. Rio de Janeiro: Editora 34.

Lévi-Strauss, C. (1989). O pensamento selvagem [The savage mind]. Tradução Tânia Pellegrini. Campinas: Papirus.

Mendes, I. A. (2012). Research as a principle of teaching and learning Mathematics. Basic text of the conference. Submitted to the Evaluation Committee of the Full Professor contest for the Teachinglearning area of the Department of Educational Practices and Curriculum of the Federal University of Rio Grande do Norte. Natal: UFRN.

Mendes, I. A. (2013). The research as a principle for the teaching and learning of mathematics. International Journal for Research in Mathematics Education, 3, 40 - 59.

Mendes, I. A. (2016). Práticas socioculturais históricas como objetos de significação para o ensino de conceitos matemáticos. In Anais. XII Encontro nacional de Educação Matemática- XII ENEM. São Paulo: SBEM. p. 1-12. Retrieved from http://sbempe.cpanel0179.hospedagemdesites.ws/enem2016/anais/palestras1.html 
Mendes, I. A., \& Farias, C. A. (Org.). (2014). Práticas socioculturais e Educação Matemática [Sociocultural Practices and Mathematics Education]. São Paulo: Ed. Livraria da Física (Coleção Contextos da Ciência).

Miguel, A., \& Mendes, I. A. (2010). Mobilizing histories in mathematics teacher education: memories, social practices, and discursive games. ZDM Mathematics Education, 42, 381-392. https://doi.org/10.1007/s11858-010-0255-8

Moles, A. A. (1974). Sociodinâmica da cultura [Sociodynamics of culture]. Tradução Mauro W. Barbosa de Almeida. São Paulo: Perspectiva (1 ${ }^{\mathrm{a}}$ reimpressão, da $1^{\mathrm{a}}$ edição, 2012). (Série: Estudos, 15).

Moles, A. A. (1981). A criação científica [Scientific creation]. Tradução Gita K. Guinsburg. São Paulo: Perspectiva. (Série Filosofia da Ciência, 03).

Silva, C. A. F. da, \& Mendes, I. A. (2016). Estudos sobre cultura e práticas sociais: contribuições para a Formação de professores de matemática [Studies on culture and social practices: contributions to the training of mathematics teachers]. In Anais. XII Encontro nacional de Educação Matemática- XII ENEM. São Paulo: SBEM. $\quad$ p. $1-12 . \quad$ Retrieved from http://sbempe.cpanel0179.hospedagemdesites.ws/enem2016/anais/autores-C.html

Silva, C. A. F. da. (2014). Estudos sobre cultura e práticas sociais: contribuições para formação de professores de matemática. Relatório de pesquisa de Pós-doutorado Júnior. Conselho Nacional de Desenvolvimento Cientifico e Tecnológico (CNPq) [Studies on culture and social practices: contributions to the training of mathematics teachers (Postdoctoral research report Júnior), National Council for Scientific and Technological Development]. Natal/Brasil.

Stenhouse, L. (1987). La investigación como base de la enseñanza. Tradução Guillermo Solana. Madrid: Ediciones Morata.

Storr, A. (2013). A dinâmica da criação. O que faz as pessoas serem mais originais [The dynamics of creation. What makes people more original]. Tradução Ana Cláudia Fonseca e Cláudia Gerpe Duarte. São Paulo: Benvirá.

Vergani, T. (1991). O zero e os infinitos: uma experiência de antropologia cognitiva e educação matemática intercultural [The Zero and the Infinites: an experience of Anthropology and Intercultural Mathematics Education]. Lisboa: Minerva.

Vergani, T. (1993). Educação Matemática - um horizonte de possíveis: sobre uma educação matemática viva e globalizante [Mathematical Education - a horizon of possible: on a living and globalizing mathematical education]. Lisboa: Universidade Aberta.

Vergani, T. (1995). Excrementos do sol. a propósito de diversidades culturais [Excrement of the sun: on the subject of cultural diversities]. Lisboa: Pandora.

Vergani, T. (2002). Matemática e linguagem(s). Olhares interactivos e transculturais [Mathematics and language (s). Interactive and cross-cultural views]. Lisboa: Pandora.

Vergani, T. (2009). A criatividade como destino: transdisciplinaridade, cultura e educação [Creativity as destiny: transdisciplinarity, culture and education]. (Org. FARIAS, Carlos Aldemir; MENDES, Iran Abreu: ALMEIDA, Maria da Conceição). São Paulo: Ed. Livraria da Física. (Coleção Contextos da Ciência). 